\title{
Intestinal Intussusception: Etiology, Diagnosis, and Treatment
}

\author{
Priscilla Marsicovetere, JD, PA-C $C^{1,2}$ S. Joga Ivatury, MD, MHA $A^{1,2,3}$ Brent White, MD $^{1,2}$ \\ Stefan D. Holubar, MD, MS ${ }^{1,2,3}$
}

${ }^{1}$ Dartmouth-Hitchcock Medical Center, Lebanon, New Hampshire

${ }^{2}$ Geisel School of Medicine, Hanover, New Hampshire

${ }^{3}$ The Dartmouth Institute for Health Policy \& Clinical Practice,

Lebanon, New Hampshire

Address for correspondence Stefan D. Holubar, MD, MS, FACS, FASCRS, Division of Colon \& Rectal Surgery, Department of Surgery, One Medical Center Drive, Lebanon, NH 03756

(e-mail: stefan.holubar@dartmouth.edu).

Clin Colon Rectal Surg 2017;30:30-39.

\begin{abstract}
Keywords

- intussusception

- intussusceptum

- intussuscipiens

- bowel obstruction

Intussusception is defined as the invagination of one segment of the bowel into an immediately adjacent segment of the bowel. Idiopathic ileocolic intussusception is the most common form in children and is typically managed with nonoperative reduction via pneumatic and/or hydrostatic enemas. In the adult population, intussusception is uncommon and occurs more often in the small intestine than in the colon. It is associated with lead point pathology in most symptomatic cases presenting as bowel obstruction. When lead point pathology is present in adult small bowel intussusception, it is usually benign, though when malignant it is most frequently due to diffuse metastatic disease, for example, melanoma. In contrast, adult ileocolic and colonic intussusception lead point pathology is most frequently primary adenocarcinoma when malignant. The diagnosis is typically made intraoperatively or by cross-sectional imaging. With increasingly frequent CT/MRI of the adult abdomen in the current era, transient and/or asymptomatic intussusceptions are increasingly found and may often be appropriately observed without intervention. When intervention in the adult population is warranted, usually oncologic bowel resection is performed due to the association with lead point pathology.
\end{abstract}

Intussusception is defined as the invagination of one segment of the bowel into an immediately adjacent segment. The intussusceptum refers to the proximal segment that invaginates into the distal segment, or the intussuscipiens (recipient segment). Intussusception, more common in the small bowel and rarely involving only the large bowel, has historically presented as small bowel obstruction, although there is an increasing appreciation of cases of transient, asymptomatic intussusception within the era of abdominal CT scans. The natural history of intussusception starts with a lead point, typically neoplastic (such as lymphadenopathy, polyp, or cancer), which acts as a focal area of traction that draws the proximal bowel within the peristalsing distal bowel. Symptoms occur due to continued peristaltic contractions of the intussuscepted segment against the obstruction. With continued invagination resulting in edema, eventually the vascular flow to the bowel becomes compromised, resulting in ischemia to the affected segment that, left untreated, can result in necrosis and perforation.

In the pediatric population, ileocolic intussusception is the most common type. The etiology of intussusception in children is typically idiopathic, often influenced by anatomic or infectious factors (- Table $\mathbf{1}$ ). The diagnosis and management in this population generally starts with nonoperative reduction of the intussusceptum using air or contrast enemas.

In the adult population, intussusception is frequently due to a pathologic lead point, which can be intraluminal, mural, or extramural. As opposed to the pediatric population, the treatment of intussusception causing obstruction in adults typically involves surgery, often with bowel resection.
Issue Theme Approaches and Treatment of Intussusception, Volvulus, Rectal Prolapse, and Functional Disorders of the Colon, Rectum, and Anus; Guest Editor: Jason S. Mizell, MD, FACS, FASCRS
Copyright $\odot 2017$ by Thieme Medical Publishers, Inc., 333 Seventh Avenue, New York, NY 10001, USA. Tel: +1(212) 584-4662.
DOI http://dx.doi.org/ $10.1055 / \mathrm{s}-0036-1593429$. ISSN 1531-0043. 
Table 1 Predisposing factors in the development of pediatric intussusception

\begin{tabular}{|c|c|c|}
\hline Anatomic & $\begin{array}{l}\text { Anatomic variation in } \\
\text { the developing } \mathrm{Gl} \text { tract }\end{array}$ & Lymphangioma \\
\hline & Appendix & Leiomyosarcoma \\
\hline & Crohn disease & Lymphomas \\
\hline & Intestinal duplication & $\begin{array}{l}\text { Meckel } \\
\text { diverticulum }\end{array}$ \\
\hline & Intestinal duplication & $\begin{array}{l}\text { Peutz-Jegher } \\
\text { polyp or cancer }\end{array}$ \\
\hline & $\begin{array}{l}\text { Hypertrophied Peyer } \\
\text { patch }\end{array}$ & Polyps \\
\hline & Lipomas & \\
\hline \multirow{7}{*}{$\begin{array}{l}\text { Associated } \\
\text { infections }\end{array}$} & Adenovirus & \\
\hline & Rotavirus & \\
\hline & Parasites & \\
\hline & Bleeding disorders & \\
\hline & $\begin{array}{l}\text { Henoch-Schonlein } \\
\text { purpura }\end{array}$ & \\
\hline & Hemophilia & \\
\hline & Leukemia & \\
\hline \multirow[t]{3}{*}{$\begin{array}{l}\text { Associated } \\
\text { diseases }\end{array}$} & $\begin{array}{l}\text { Neuronal intestinal } \\
\text { dysplasia }\end{array}$ & \\
\hline & Celiac disease & \\
\hline & Cystic fibrosis & \\
\hline
\end{tabular}

Abbreviation: Gl, gastrointestinal tract.

\section{Etiology}

Intussusception results from the alteration of normal peristalsis by a lesion in the bowel wall that creates invagination. It can occur anywhere in the small and large intestine. The nomenclature of intussusception reflects location of both the intussusceptum and intussuscipiens in the bowel: enteroenteric, appendiceal, appendiceal-ileocolic, ileocolic, colocolic, rectoanal, and stomal intussusception. For the purpose of this article, rectoanal and stomal intussusception will not be discussed as they are better characterized as (extracorporeal) prolapse. The upper gastrointestinal structures, specifically the esophagus, stomach, and duodenum, are rarely involved in intussusception due to their lack of mobility, redundancy, and characteristic anatomic fixation. Moreover, the most common locations are at the junctions between freely moving segments and areas that are fixed, such as to the retroperitoneum (i.e., the fully peritonealized and mobile ileum intussuscepting into the fixed, retroperitoneal cecum) or through adhesions.

\section{Pediatric Etiology}

Intussusception is most commonly encountered in children and has been reported to be the most common abdominal emergency in early childhood and the second most common cause of intestinal obstruction after pyloric stenosis. ${ }^{1}$ The mean age of intussusception in children is 6 to 18 months, with a male predominance. The incidence of intussusception declines with age-only $30 \%$ of all cases occur in children older than 2 years. Ileocolic intussusception is the most common form of intussusception in children.

The etiology of pediatric intussusception is usually idiopathic, with only $10 \%$ of cases having an identifiable precipitating lesion. ${ }^{2}$ Several predisposing factors are thought to contribute to the pathophysiology of pediatric intussusception (-Table 1 ).

Certain anatomic features in the developing gastrointestinal tract may predispose the pediatric bowel to an intussusception, including an anterior insertion of the terminal ileum with respect to the cecum, decreased rigidity of the cecum secondary to the absence or underdeveloped taeniae coli, and lack of mature participation of the longitudinal muscle fibers of the colon at the level of the ileocecal valve. These variations were identified by Scheye et $\mathrm{al}^{3}$ in a postmortem evaluation of 15 autopsy specimens, with 3 of the specimens being used for detailed evaluation of ileocecal valve anatomy. The development of intussusception may thus result from the invagination of the muscular ileocecal valve into the cecum due to the decreased rigidity of the cecal wall caused by the paucity of developed taeniae coli.

Infectious etiology resulting in mesenteric lymphadenopathy is another common cause of pediatric intussusception. Hypertrophy of the Peyer patches in the setting of common viral illness such as adenovirus and rotavirus can lead to intussusception. Buettcher et al found a seasonal variation of intussusception that correlated with seasonal variation of viral gastroenteritis. ${ }^{4}$ Approximately $30 \%$ of patients experience an antecedent viral illness before the onset of intussusception.

Intussusception can also be caused by noninfectious etiologies, such as intestinal allergies, Celiac disease, and Crohn disease. Similar to infectious causes, hypertrophy of Peyer patches and/or mesenteric lymphadenopathy can act as a lead point. Unlike in the adult population, neoplasia is a rare etiology of intussusception in children; but if a neoplastic etiology is present, lymphoma is most common in the pediatric population, as opposed to adenocarcinoma in adults.

Additionally, altered peristalsis in focal areas of the bowel wall leading to aperistaltic segments that feed into peristaltic areas, as in the submucosal hemorrhages in Henoch-Schonelin purpura, allows for the formation of an intussusceptum. Functional bowel disorders, and poorly understood neuroenteric disorders such as small intestinal pseudoobstruction, can alter peristalsis and result in intussusception in a similar fashion. Aperistaltic segments may be conceptualized as lead points.

Although the majority of pediatric cases do not have an identifiable etiology, in approximately $10 \%$ a lead point or underlying cause will be found. Congenital gastrointestinal tract abnormalities such as Meckel diverticulum, intestinal duplication, or the presence of lesions such as polyps, hamartomas, or malignancies (lymphoma, carcinoma due to juvenile polyposis syndromes) can all result in intussusception. In pediatric patients with cystic fibrosis, foreign bodies, intestinal parasites, and inspissated feces may result in lead points in the ileum causing ileocolic intussusception. 
With increasing age, the likelihood of identifiable causes of intussusception increases.

Malrotation is another etiology of intussusception in a condition called Waugh syndrome. ${ }^{5,6}$ The pathophysiology involves prolapse of the ileocolic region into the non-fixed ascending colon in the midabdomen in children with malrotation. As the ascending colon is not fixed to the retroperitoneum, the intussusceptum often advances into the descending colon and rectum without compromising the vascularity of the bowel. At the time of surgery for malrotation and intussusception, the diagnosis is usually made and confirmed by the location of the cecum and the pathognomic presence of peritoneal bands from the ascending colon across the duodenum. As nonoperative reduction is a common practice for pediatric intussusception, practitioners should be aware of the possibility of Waugh syndrome.

\section{Adult Etiology}

Adult intussusception is rare, accounting for only 1 to $5 \%$ of bowel obstructions. ${ }^{2,7}$ The causes of nonidiopathic adult intestinal intussusception are shown in -Table 2. The mean age of

Table 2 Causes of nonidiopathic adult intestinal intussusception

\begin{tabular}{|l|}
\hline Enteric benign \\
\hline Adhesions \\
Adenoma \\
Cantor tubes \\
Celiac disease \\
Crohn disease \\
Endometriosis \\
Malignant stromal (GIST) tumor \\
Hamartoma \\
Hemangioma \\
Inflammatory polyp \\
Kaposi sarcoma \\
Lipoma \\
Meckel diverticulum \\
Neurofibroma \\
Peutz-Jegher polyp \\
Tuberculosis \\
Submucosal hemorrhages from unregulated \\
anticoagulation \\
\hline Enteric malignant \\
\hline Adenocarcinoma \\
Carcinoid tumor \\
Leiomyosarcoma \\
Lymphoma \\
Metastatic carcinoma (melanoma most common) \\
Malignant GIST \\
Neuroendocrine tumor \\
\hline Colonic benign \\
\hline Adenoma \\
Inflammatory pseudopolyp \\
Lipoma \\
\hline Colonic malignant \\
\hline Adenocarcinoma \\
Lymphoma \\
Sarcoma \\
\hline
\end{tabular}

intussusception in adults is 50 years with no gender predominance. In direct contrast to pediatric etiologies, adult intussusception is associated with an identifiable cause in $90 \%$ of symptomatic cases with an idiopathic cause in $10 \%$ of cases.,

Benign or malignant neoplasms cause two-thirds of cases with a lead point; the remaining cases are caused by infections, postoperative adhesions, Crohn granulomas, intestinal ulcers (Yersinia), and congenital abnormalities such as Meckel diverticulum. Of the cases caused by neoplasms, 50\% of them are malignant. ${ }^{8-10}$ Independent predictors of malignancy include colonic intussusception and anemia (hemoglobin $<12$ g/dL).

Most adult intussusceptions arise from the small bowel, and most lesions are benign with a rate of 50 to $75 \%$ in most series. $^{2,8-10}$ The most common lesions are Meckel diverticulum and adhesions. ${ }^{8}$ Benign tumors include lymphoid hyperplasia, lipomas, leiomyomas, hemangiomas, and polyps. Other conditions that predispose to small bowel intussusception include anorexia, nervosa, and malabsorption syndromes, as increased flaccidity of the bowel wall facilitates invagination. Supratherapeutic anticoagulation therapy may cause submucosal hemorrhages that can lead to intussusception.

Less commonly, malignant tumors may act as lead points with metastatic disease (i.e., carcinomatosis) being the most common. In several reports, approximately $50 \%$ of malignant lesions causing small bowel intussusception were metastatic (miliary) melanomas. ${ }^{8}$ Malignant intraluminal causes of small bowel intussusception include primary leiomyosarcomas, adenocarcinoma, GIST tumors, carcinoid tumors, neuroendocrine tumors, and lymphomas.

Adult intussusception less commonly occurs in the colon than in the small bowel and accounts for only 20 to $25 \%$ of all intussusceptions in most reported case series..$^{2,8-10}$ The most common malignant cause of colonic intussusception is primary colonic adenocarcinoma and the most common benign cause is colonic lipoma. Contrary to the small intestine, several reports indicate that colonic intussusception is more likely to have a malignant lead point due to the increased prevalence of malignancies in the colon versus the small bowel. ${ }^{10}$ However, other studies conflict with this and suggest the proportion of benign and malignant lesions causing colonic intussusception is similar to that of small bowel intussusception. Ileocolic intussusception in adults is a unique variant in which nearly $100 \%$ of cases have a malignant lead point, namely, cecal adenocarcinoma involving the ileocecal valve. ${ }^{9}$

The etiologies of adult intussusception defined earlier apply mainly to the Western developed world. In central and western Africa, primary adult intussusception is known as "Ibadan intussusception" or "tropical intussusception" and is most commonly cecocolic. ${ }^{11}$ This geographic variation in pathology has been attributed to the fiber content of the diet, dietary habits, genetics, and gut microbiome composition.

\section{Clinical Presentation}

The clinical presentation of intussusception is variable but generally marked by abdominal pain and signs of bowel obstruction. In the pediatric population, it is one of the most common abdominal emergencies. Children younger 
than 2 years classically present with acute onset colicky abdominal pain, knees drawn to chest, with excessive irritability and crying. The child may return to their usual level of activity between bouts, or they may appear listless and lethargic as the pain becomes progressively more intense. Shortly after the onset of pain, vomiting may occur. Nearly half of cases progress to stool mixed with blood and mucus, giving it a "currant jelly" appearance. Physical exam may reveal a palpable "sausage-shaped mass" in the right upper quadrant or epigastric region of the abdomen, but the mass is only detected in approximately $60 \%$ of cases. The classic pediatric triad of abdominal pain, palpable abdominal mass, and bloody stool is quite rare, present in less than $15 \%$ of cases. ${ }^{12}$

In adults, the clinical presentation of intussusception can be nonspecific, rarely presenting with the classic triad of abdominal pain, palpable mass, and bloody stool. ${ }^{13-15}$ Instead, it presents with symptoms of small or large bowel obstruction. The most common presenting symptom is abdominal pain, ${ }^{14,16}$ with associated symptoms consistent with partial obstruction: nausea, vomiting, obstipation, gastrointestinal bleeding, change in bowel habits, constipation, or bloating. ${ }^{15,17}$ Wang et al found abdominal cramping pain in nearly $80 \%$ of patients as a leading symptom; a palpable abdominal mass, however, was found in less than $9 \% .{ }^{10}$ Symptoms are typically acute, lasting days to weeks, ${ }^{15}$ but rarely can be chronic, lasting years. ${ }^{18}$ The onset and duration of clinical symptoms is significantly longer in large bowel than in small bowel disease, 62.5 versus $35.7 \%$ respectively. ${ }^{19}$

Physical exam reveals a distended abdomen, with tenderness ranging from mild to severe (consistent with parietal peritoneal irritation). Decreased or absent bowel sounds, guaiac-positive stool, and an abdominal mass may be present. ${ }^{16}$ If the presentation is late in the course of the disease, the patient may present with signs of peritonitis or bowel ischemia with pain out of proportion to physical exam findings. In addition, signs of shock such as hypotension and tachycardia may be present. The nonspecific nature of these findings, coupled with the rarity of intussusception incidence in adults, can result in a broad differential diagnosis and may not include intussusception. Laboratory values typically reveal an elevated white blood cell count and nonspecific inflammatory markers/acute phase reactants such as thrombocytosis and elevated C-reactive protein. $^{20}$ - Table 3 summarizes recently published case series of adult intussusception regarding presenting symptoms(s), diagnosis, and final pathology.

\section{Patient Evaluation}

The assessment of intussusception differs in pediatric and adult populations. In children, intussusception is typically idiopathic and benign, and diagnosis can be expedited by having a high index of suspicion. In adults, it typically represents obstruction from a potentially malignant etiology. In either case, quick, less invasive, and less costly approaches are initially employed in the making of the diagnosis. Evaluation often starts with plain films of the abdomen (acute abdominal series). Plain films will typically reveal signs of intestinal obstruction or perforation, which may include massively distended loops of bowel with absence of colonic gas, as well as information on the location of the obstruction in the gastrointestinal tract. ${ }^{14}$ Additional radiographic findings include a target sign, consisting of two concentric radiolucent circles superimposed on the right kidney which represents peritoneal fat surrounding the intussusception ${ }^{21}$; an obscured liver margin ${ }^{22}$; or lack of air in the cecum, preventing its visualization. While plain films are deemed useful in the diagnosis of obstruction, they lack sensitivity and specificity for diagnosing intussusception. ${ }^{14}$ A 2008 study of 72 intussusception patients found that plain films were of little to no use in making the diagnosis, with $0 \%$ detection rate. ${ }^{19}$ More recently, in a study that analyzed clinical and radiological findings in an attempt to provide a decision tree, more than $20 \%$ of patients with intussusception had negative plain films. ${ }^{23}$ Although they may not make the diagnosis, they clearly have a role in objectifying the bowel obstruction and occult pneumoperitoneum.

Unlike plain films, the sensitivity and specificity of ultrasound in diagnosing intussusception approaches nearly $100 \%$ in experienced hands, especially in children. ${ }^{24}$ Due to the noninvasive nature of ultrasound, it is the imaging modality of choice for evaluating children, and has been found to be a rapid, sensitive screening procedure in the assessment for intussusception. The classic feature is the target or doughnut sign caused by the edematous intussuscipiens forming an external ring around the centrally based intussusceptum. ${ }^{25}$ On the transverse view, the pseudo-kidney appearance is formed by the layers of the intussusception. In adults, however, ultrasound tends to be less accurate than in children, but may still reveal classic features of the target or doughnut sign on the transverse view and pseudo-kidney on the longitudinal view. Color Doppler may be used to demonstrate decreased blood flow to the intussusceptum if bowel is ischemic. Limitations to ultrasound accuracy include massive air in cases of bowel distension or morbid obesity, both of which can result in a decreased rate of detection and diagnosis of intussusception. ${ }^{14}$

In adults, given the nonspecific nature of the clinical presentation and the wide differential, choice of imaging modality is important to arrive at a timely diagnosis. In a series reported by Guillén Paredes et al, diagnostic studies used to assess 12 cases of adult intussusception included abdominal $\mathrm{X}$-ray, ultrasound, CT, pre-op colonoscopy, and opaque enema. ${ }^{20}$ Findings supported an order of diagnostic accuracy as follows: CT ( 8 out of 10 patients), followed by ultrasound ( 6 of 12 patients), followed by opaque enema ( 2 of 4 tests performed), and colonoscopy ( 2 of 5 tests performed); no mention was made of the accuracy of abdominal X-rays. Diagnostic accuracy of CT has been found to be as high as 58 to $100 \%$ in other reports. ${ }^{14,19}$ Recently, Ciftci found in a small study of six patients that CT was ideal for the diagnosis of intussusception. ${ }^{26}$ In that same study, ultrasound was found to be of less utility in diagnosing intussusception. This was owing to potentially limiting factors such as bowel wall edema and sigmoid volvulus, which appear on ultrasound with the same target and ox eye signs as intussusception. Additionally, 
34 Intestinal Intussusception Marsicovetere et al.

Table 3 Presentation and etiology of adult intussusception

\begin{tabular}{|c|c|c|c|c|c|}
\hline & $\begin{array}{l}\text { Ciftci } \\
(2015)^{26}\end{array}$ & $\begin{array}{l}\text { Honjo et al } \\
(2014)^{34}\end{array}$ & $\begin{array}{l}\text { Sarma et al } \\
(2012)^{16}\end{array}$ & $\begin{array}{l}\text { Cakir et al } \\
(2012)^{35}\end{array}$ & $\begin{array}{l}\text { Guillén Paredes et al } \\
(2010)^{20}\end{array}$ \\
\hline Patients & 6 & 44 & 15 & 47 & 14 \\
\hline$M / F$ & $3 / 3$ & $20 / 24$ & $7 / 8$ & $23 / 24$ & $7 / 7$ \\
\hline Average age (y) & 40 & 70 & 44.5 & 49 & 41.9 \\
\hline Median duration of $s x$ & $2.33 \mathrm{~d}$ & Acute to $1 \mathrm{mo}$ & $\begin{array}{l}6 \text { acute } \\
9 \text { chronic }\end{array}$ & $17 \mathrm{~d}$ & \\
\hline \multicolumn{6}{|l|}{ \#1 Symptom } \\
\hline Abd pain & $100 \%$ & $54.5 \%$ & $100 \%$ & $100 \%$ & $50 \%$ \\
\hline Constipation & & & $40 \%$ & & $4.54 \%$ \\
\hline $\mathrm{N} / \mathrm{V}$ & $66 \%$ & $36.3 \%$ & $60 \%$ & $100 \%$ & \\
\hline Diarrhea & & $18.2 \%$ & & & \\
\hline GI bleed & $16 \%$ & $13.6 \%$ & $15 \%$ & $2.1 \%$ & $9.09 \%$ \\
\hline Mass & & $11.4 \%$ & $20 \%$ & & $13.63 \%$ \\
\hline Obstruction & & & & & $18.18 \%$ \\
\hline Dx pre-op & & $95 \%$ & & & $85.7 \%$ \\
\hline SB & $83 \%$ & $27.3 \%$ & $53.3 \%$ & $9 \%$ & $35.7 \%$ \\
\hline LB & $16 \%$ & $22.7 \%$ & $6 \%$ & $8 \%$ & $14.3 \%$ \\
\hline ICV & & $50 \%$ & $40 \%$ & $84 \%$ & $57.1 \%$ \\
\hline Path Dx total & & $77.3 \%$ & & & \\
\hline Idiopathic & $16 \%$ & $11.4 \%$ & & $13 \%$ & \\
\hline Total benign & & $20.4 \%$ & $6.6 \%$ & $53 \%$ & \\
\hline Total Malig & & $56.8 \%$ & & $34 \%$ & \\
\hline Benign SB & $83 \%$ & $5 \%$ & $26.7 \%$ & $47 \%$ & $21.4 \%$ \\
\hline Malig SB & & $7 \%$ & $6.6 \%$ & $4 \%$ & $14.3 \%$ \\
\hline Malig Ileocolic & & $25 \%$ & $33.3 \%$ & & $28.6 \%$ \\
\hline Malig LB & $16 \%$ & $20.5 \%$ & & $30 \%$ & \\
\hline Benign LB & & $2.3 \%$ & & & $14.3 \%$ \\
\hline
\end{tabular}

Abbreviations: Abd, abdominal; constip, constipation; Dx, diagnosis; Gl, gastrointestinal; ICV, ileocolic volvulus; LB, large bowel; malig, malignant; N/ $\mathrm{V}$, nausea/vomiting; SB, small bowel; sx, symptoms.

decreased reliability was noted due to air levels in the bowel, a large amount of feces in the colon and malrotation. Similarly, Guillén Paredes et al found that despite the fact that ultrasound was used more frequently, it did not guarantee a diagnosis on most occasions and abdominal CT was recommended. Classic findings on CT include "target," "bulls-eye," or sausage-shaped lesions as a concentric hyperdense double ring, features owing to the anatomic configuration of the outer intussuscipiens and the central intussusceptum creating a bowel-within-bowel appearance (-Figs. 1-4). ${ }^{13,14,19}$

Additionally, mesenteric vessels within the bowel lumen are characteristic on $\mathrm{CT}$, showing compromised vascular perfusion in terms of venous stasis, edema, and air in the bowel wall due to necrosis or gangrene. ${ }^{14}$ Despite the benefits of CT, MartínLorenzo et al found that while CT is extraordinarily sensitive for detecting intussusception, it is limited by less accessibility, a static and single plane exploration, radiation, and finally oral and IV contrast which could further delay the study and thus the proper diagnosis. ${ }^{18}$ As such, CT was thought best limited to use in chronic cases, and ultrasound in the hands of experienced radiologists could possibly have a sensitivity and specificity close to that of CT. An additional consideration should be kept in mind: with modern, fast 65-slice, and higher CT scans, nonpathologic transient short-segment intussusceptions are commonly seen; these phenomena must be put in the proper clinical context, however, and can usually be ignored.

Additional imaging modalities can also have benefit in the evaluation of intussusception. Barium or water-soluble contrast (Gastrografin) enema may be useful in adult patients with colonic or ileocolic intussusception, revealing a characteristic "cup-shaped" filling defect, ${ }^{27}$ while also having a therapeutic effect. It is especially useful in colic or ileocolic intussusception. ${ }^{18}$ In the pediatric population, hydrostatic or pneumatic enema is limited to therapeutic applications. Barium studies are contraindicated if there is a possibility of bowel perforation or ischemia due to the risk of "barium 

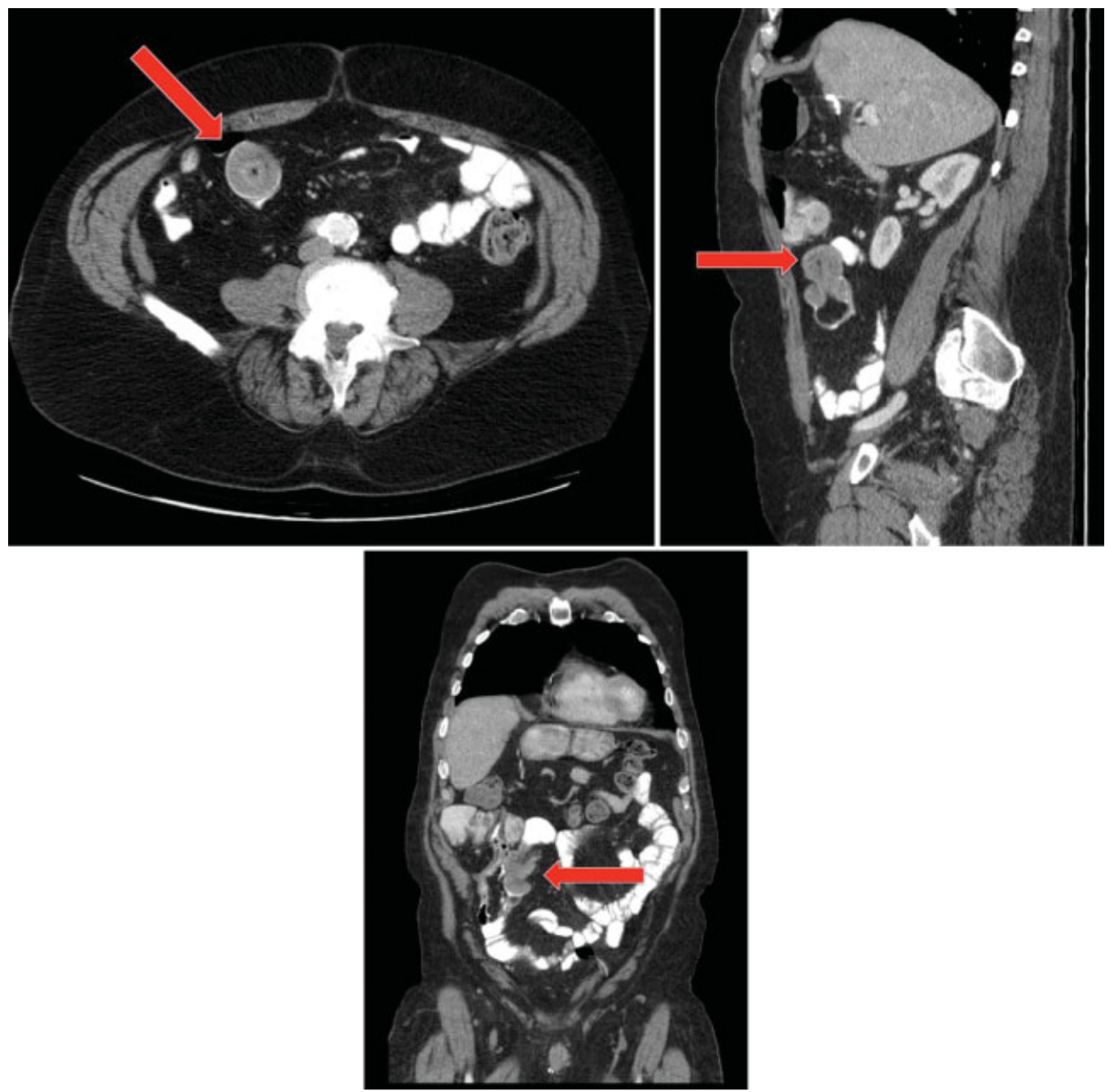

Fig. 1 lleoileal adult intussusception with classic "bulls-eye" appearance with concentric rings (left panel) and obvious invagination (middle and right panels). (Images courtesy of Dr. Nancy McNulty, MD.)

peritonitis." Colonoscopy is another useful tool in evaluating intussusception, notably when the presenting symptoms include a large bowel obstruction; it allows the lesion to be diagnosed and biopsied. Caution must be exercised with colonoscopic biopsy, however, due to an increased risk of perforation resulting from chronic tissue ischemia, vascular compromise, and potentially necrosis. Another transient phenomenon is the inverted appendix, which, after ruling out mass lesion by cross-sectional imaging, can often be observed. With this condition, the patient will usually be asymptomatic. MRI is not routinely used in the pediatric or adult populations in the diagnosis of intussusception, but its sensitivity may be similar to $\mathrm{CT}$, especially when an enterography protocol is used (-Fig. 5).

\section{Treatment}

In the pediatric population, treatment depends on the type of intussusception. Ileocolic intussusception, the most common type in children, requires reduction by ultrasound-guided or fluoroscopic pneumatic or hydrostatic enema, and is successful in 85 to $90 \%$ of cases. ${ }^{28}$ Close observation is required due to the heightened possibility of recurrence within the first 24 hours. Small bowel intussusception, which is uncommon in children, can usually be safely monitored and will reduce spontaneously without surgery. ${ }^{28}$ Persistent small bowel intussusception, however, has been associated with a lead point or bowel necrosis, and would likely require surgical intervention. ${ }^{29}$ Regardless of intussusception type, surgery is indicated when enema reduction or close observation is unsuccessful.

Additionally, surgery is required if there are signs of bowel necrosis. Historically, adult intussusceptions have been treated surgically due to the association of pathology serving as lead point. More recently, however, widespread use of CT/MRI imaging has resulted in increased frequency of the radiographic diagnosis of intussusception-this may be associated with equivocal gastrointestinal symptoms or none at all. ${ }^{30}$ As such, retrospective studies have demonstrated successful nonoperative management in as many as $82 \%$ of radiographic intussusceptions, even in the setting of gastrointestinal symptoms. ${ }^{31,32}$ This has created some degree of controversy regarding optimal management of these patients.

Several key clinical conditions and findings on imaging can assist the surgeon faced with adult intussusception to 

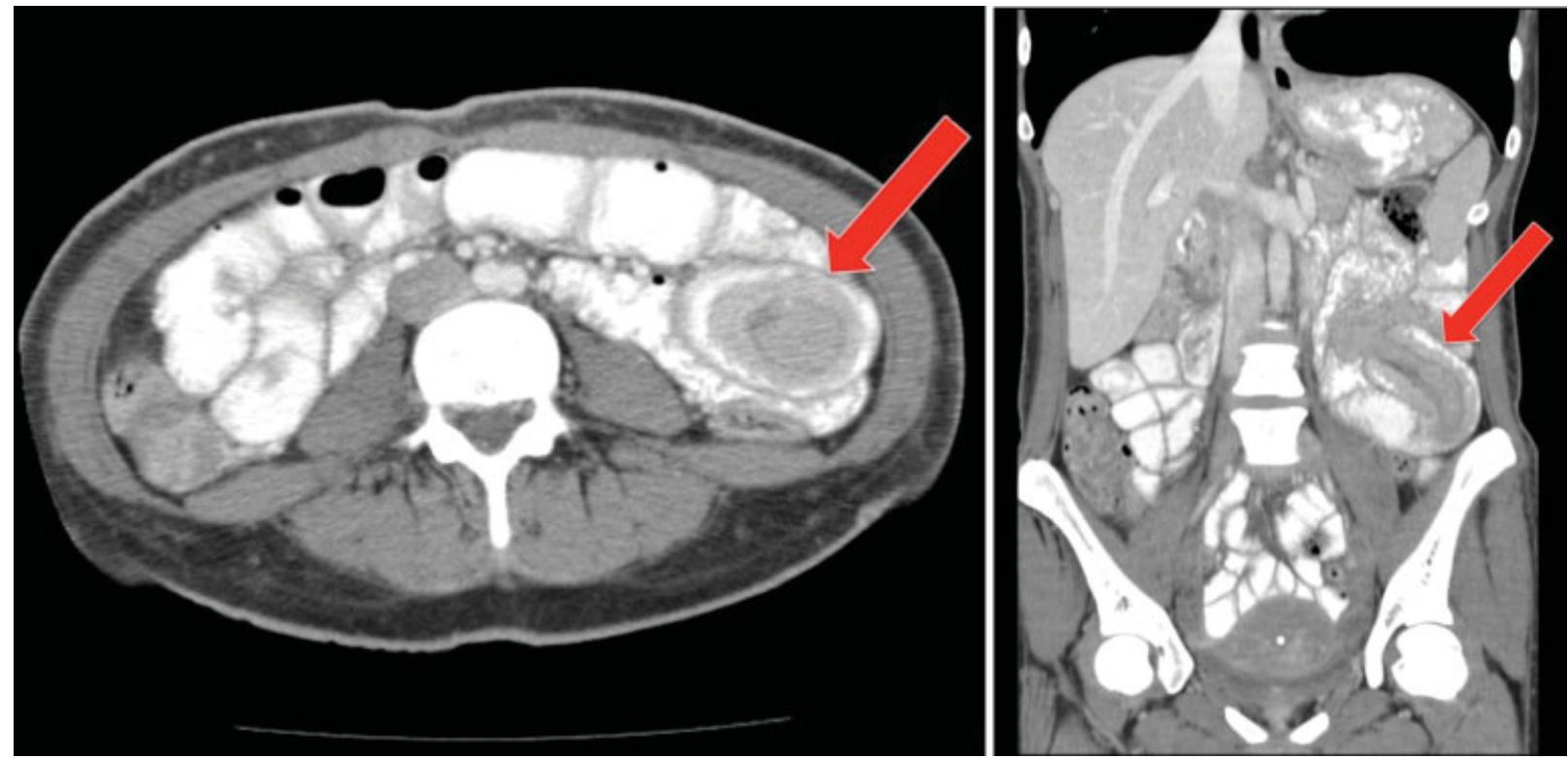

Fig. 2 Long-segment lleoileal adult intussusception with classic "bulls-eye" appearance with concentric rings (left panel) and trilaminar appearance (right panel).
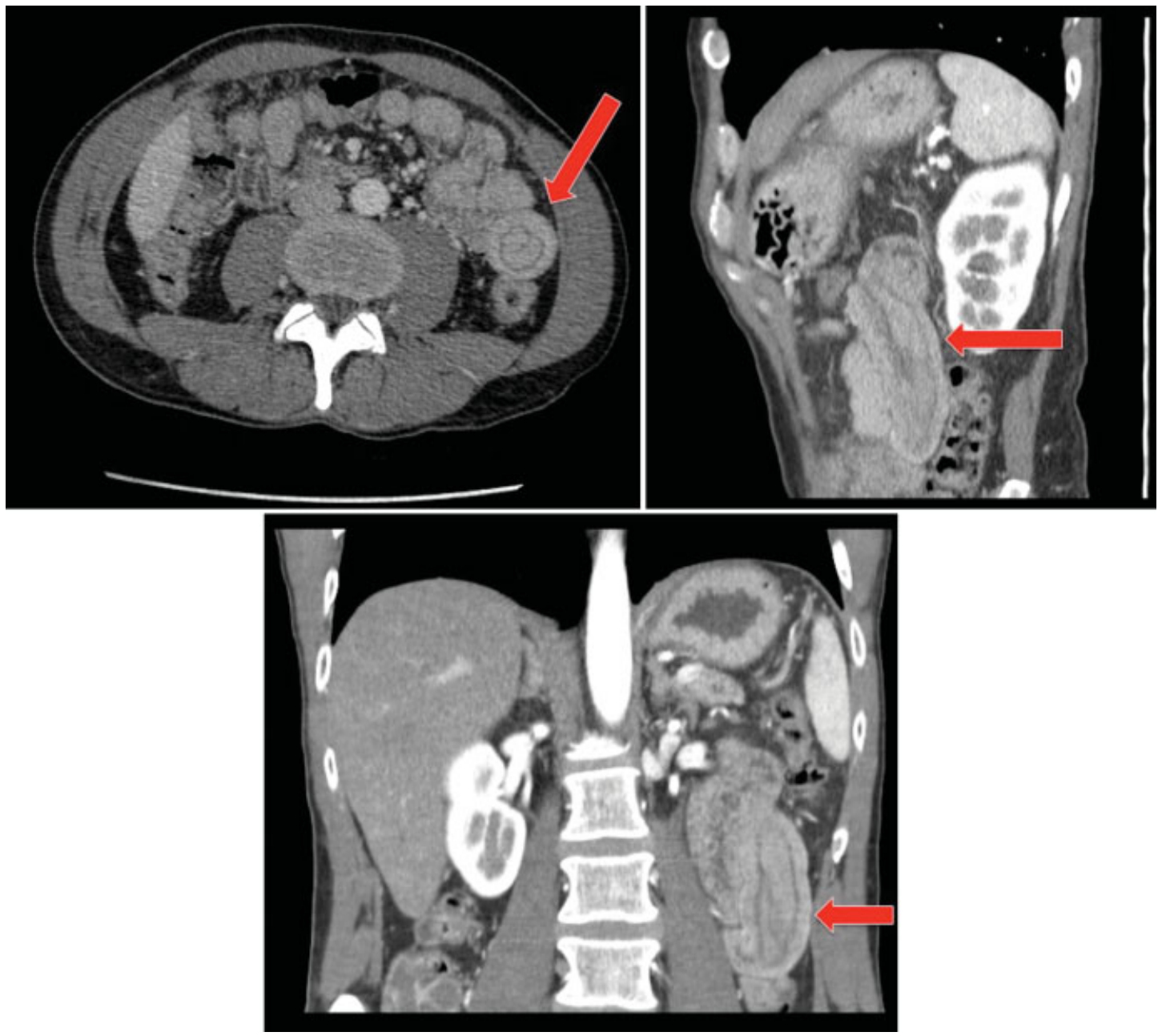

Fig. 3 Ileoileal adult intussusception with classic "bulls-eye" appearance (left panel) and "sausage-shaped mass" (middle and right panels) with multiple layers of bowel wall superimposed upon one another. (Images courtesy of Dr. Nancy McNulty, MD.) 

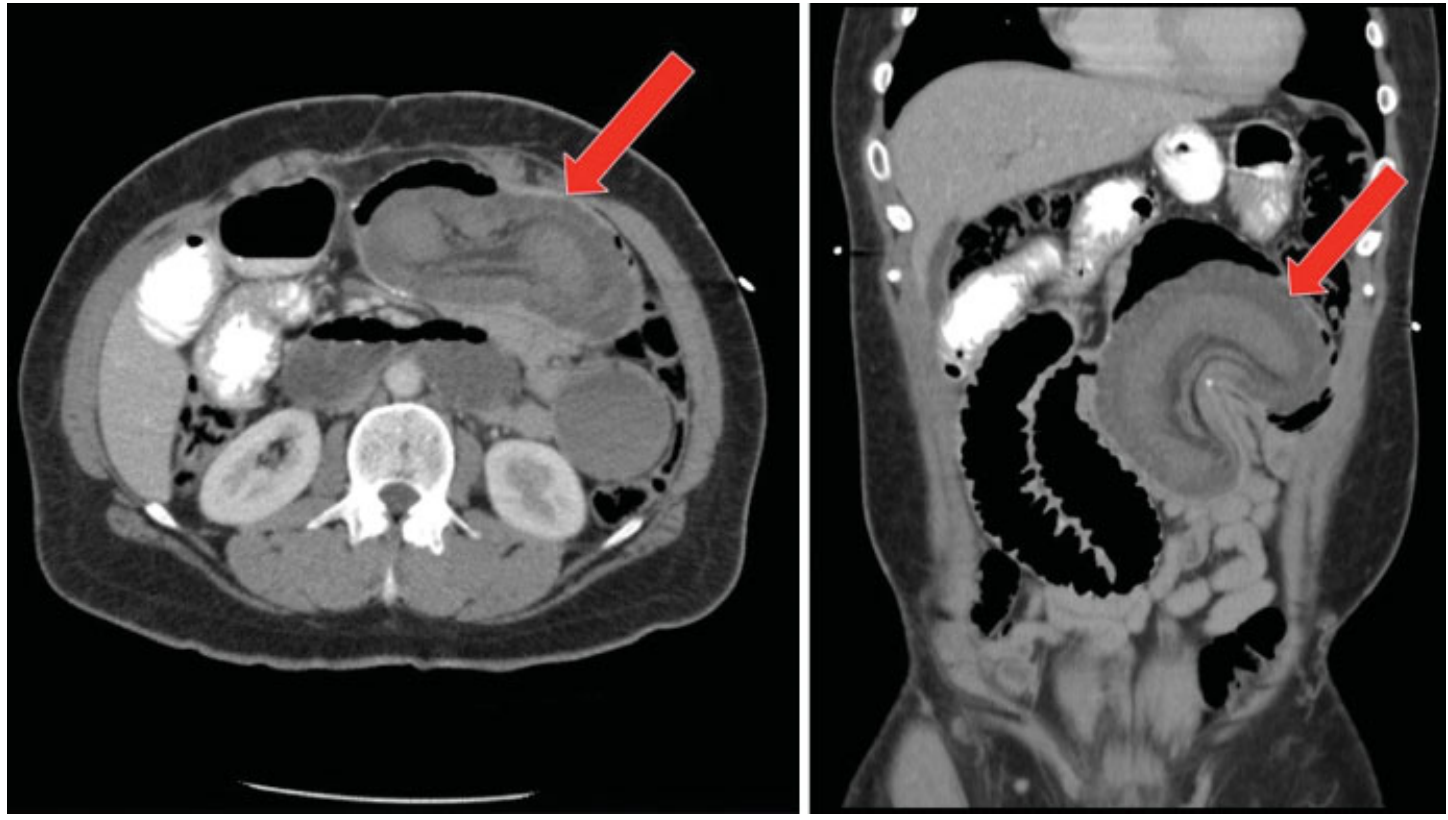

Fig. 4 Jejunal intussusception through a "JJ" anastomosis after a Roux-en-Y gastric bypass, with associated signs of small bowel obstruction.
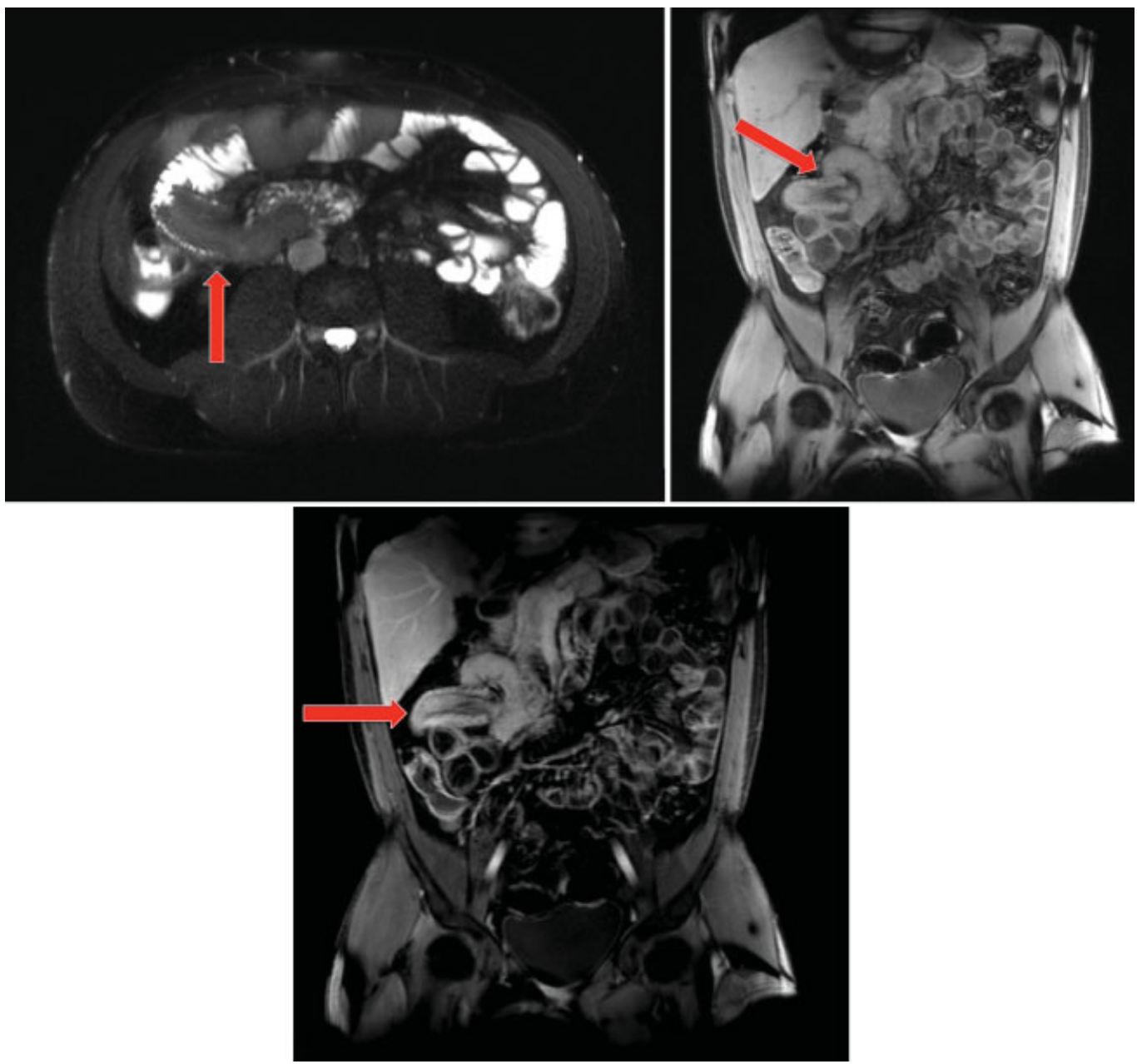

Fig. 5 Magnetic resonance enterography (MRE). Left panel demonstrates a sausage-shaped filling defect in the right hemi-abdomen; the middle (contrast enhanced) and right (postcontrast) panels demonstrates the invagination. (Images courtesy of Dr. Nancy McNulty, MD.) 
confidently proceed with surgical exploration: (1) intussusception with associated signs or symptoms of clinical obstruction, (2) intussusception with a lead point mass appreciated on cross-sectional imaging studies, and (3) colocolonic or ileocolic intussusception given the high association with malignancy in many of these cases, particularly ileocolic. In the setting of colocolonic or ileocolic intussusception, preoperative colonoscopy can frequently be pursued to confirm the presence of pathology and/or malignancy. In the large majority of entero-enteric intussusceptions without lead point mass and short affected segments-defined as less than 3.5 to $3.8 \mathrm{~cm}$ in several series-expectant management can be employed with serial clinical and imaging evaluations where necessary to ensure resolution. ${ }^{31-33}$

When indicated, surgery may be performed laparoscopically or open, depending on the skill and experience of the surgeon. Regardless of the approach, the intussusception must be successfully identified and then carefully reduced (in children) or resected (adults). When preoperative colonoscopy, imaging studies or intraoperative appearance strongly suggests the presence of malignancy, or the surgeon suspects ischemia such that reduction would uncover a gangrenous segment at risk of perforation with even gentle manipulation, reduction is ill advised and the entire segment should be resected en bloc. In these cases, efforts should be made to resect the unreduced intussusception using oncologic principles so as to minimize risk of spillage and contamination of the abdominal cavity with cancer cells; lymphadenectomy of the major draining vessel(s) should be performed obtaining $\geq 12$ lymph nodes to facilitate proper prognosis and chemotherapeutic treatment recommendations. Generally, resection of the pathologic and/or ischemic segment of bowel with creation of a primary surgical anastomosis can be performed in entero-enteric intussusceptions and right-sided colocolonic or ileocolic intussusception. In instances of left-sided colonic intussusception with associated obstruction, a resection with Hartmann procedure is the generally recommended approach, although both a primary anastomosis and primary anastomosis with proximal diverting loop ileostomy may be considered depending on the situation and risk factors for anastomotic leak. The presence of high-dose steroids, chemotherapy, and other powerful immunosuppressives, malnutrition and smoking may all obviate a primary anastomosis even in the small bowel.

Regarding surgical approach, for open cases (i.e., laparotomy) standard surgical technique using a midline incision and wound protector with or without a fixed retracting system (i.e., Bookwalter) is used. Despite the typical urgent or emergent nature of these cases, infection prevention measures (e.g., optimal antibiotic selection and re-dosing, peritoneal cavity and wound antibiotic irrigation, changing of gloves, suction, and Bovie tip for closing) should be utilized.

For laparoscopic cases, we utilize a 4-cm periumbilical "question-mark"-shaped initial incision, with a small wound protector; this incision will ultimately be used for specimen extraction and for construction of the extracorporeal anastomosis. A 12-mm sleeve, which accepts a laparoscopic stapling device, is secured in place with Teflon tape. Pneumoperitoneum is then established, and two additional 5-mm ports are placed, one in the left lower quadrant and the other suprapubically (in the case of enteroenteric or ileocolic intussusception). This port placement allows excellent access to the entire small bowel, cecum, ascending colon, and proximal one-half of the transverse colon, ileocolic, artery, transverse colic arteries, and root of the small bowel mesentery. All four quadrants of the abdomen and the pelvis are thoroughly explored. Suspicious fluid is sampled for culture and suspicious lesions biopsied. Other ports are placed as needed depending on the location of the pathology. Atraumatic graspers (such as endo-Babcock graspers) are used to run the small bowel in a retrograde manner starting at the ileocecal valve, and using the hand-over-hand technique to carefully grasp the mesenteric edge, not the bowel wall. After the pathologic segment is found, it can either be resected intracorporeally using a stapling device for the bowel and stapler or energy device for the mesentery, or eviscerated and dealt with extracorporeally. In the case of pediatric intussusception, only 5-mm ports are used and the reduction can be performed entirely intracorporeally (-Video 1 ).

\section{Video 1}

Intracorporeal reduction of pediatric intussusception using 5-mm ports. Courtesy of Daniel P. Croitoru, MD. Online content including video sequences viewable at: www.thieme-connect.com/ejournals/html/doi/ 10-1055-s-0036-1593429-ccrs-765-v1.mp4.

\section{Conclusion}

Intussusception is a common and often benign condition in the pediatric population, and can usually be managed nonoperatively. The condition is rare in adults, however, and is often a challenging diagnosis due to nonspecific symptoms. Surgeons must therefore be familiar with the epidemiology, etiology, diagnosis, and treatment of both pediatric and adult intussusception. Despite their rarity, most general and colon and rectal surgeons will treat patients with intussusception, and optimal outcomes will only be achieved by understanding the earlier-outlined principles.

\section{Note}

The previous version of this article was authored by Susan M. Cera, MD.

\section{References}

1 Lloyd DA, Kenny SE. The surgical abdomen. In: Walker WA, Goulet O, Kleinman RE, et al, eds. Pediatric Gastrointestinal Disease: Pathophysiology, Diagnosis, Management. 4th ed. Ontario, Canada: BC Decker; 2004:604

2 Begos DG, Sandor A, Modlin IM. The diagnosis and management of adult intussusception. Am J Surg 1997;173(2):88-94

3 Scheye Th, Dechelotte P, Tanguy A, Dalens B, Vanneuville G, Chazai J. Anatomical and histological study of the ileocecal valve: possible 
correlations with the pathogenesis of idiopathic intussusception in infants. Surg Radiol Anat 1983;5(2):83-92

4 Buettcher M, Baer G, Bonhoeffer J, Schaad UB, Heininger U. Threeyear surveillance of intussusception in children in Switzerland. Pediatrics 2007;120(3):473-480

5 Rao PL, Kumar V. Waugh's syndrome. Indian J Pediatr 2005;72(1):86

6 Al-Momani H. Waugh syndrome: a report of 7 patients and review of the published reports. Ann Saudi Med 2014;34(6):527-531

7 Eisen LK, Cunningham JD, Aufses AH Jr. Intussusception in adults: institutional review. J Am Coll Surg 1999;188(4):390-395

8 Azar T, Berger DL. Adult intussusception. Ann Surg 1997;226(2): 134-138

9 Zubaidi A, Al-Saif F, Silverman R. Adult intussusception: a retrospective review. Dis Colon Rectum 2006;49(10):1546-1551

10 Wang LT, Wu CC, Yu JC, Hsiao CW, Hsu CC, Jao SW. Clinical entity and treatment strategies for adult intussusceptions: 20 years' experience. Dis Colon Rectum 2007;50(11):1941-1949

11 VanderKolk WE, Snyder CA, Figg DM. Cecal-colic adult intussusception as a cause of intestinal obstruction in Central Africa. World J Surg 1996;20(3):341-343, discussion 344

12 West KW, Stephens B, Vane DW, Grosfeld JL. Intussusception: current management in infants and children. Surgery 1987;102(4):704-710

13 Elm'hadi C, Tarchouli M, Khmamouche MR, et al. Intestinal intussusception in a young women: unusual cause and specific management. World J Surg Oncol 2015;13:252

14 Mrak K. Uncommon conditions in surgical oncology: acute abdomen caused by ileocolic intussusception. J Gastrointest Oncol 2014;5(4):E75-E79

15 McKay R. Ileocecal intussusception in an adult: the laparoscopic approach. JSLS 2006;10(2):250-253

16 Sarma D, Prabhu R, Rodrigues G. Adult intussusception: a six-year experience at a single center. Ann Gastroenterol 2012;25(2):128-132

17 Voore N, Weisner L. Unusual cause of intussusception. BMJ Case Rep 2015. doi: 10.1136/bcr-2015-212324

18 Martín-Lorenzo JG, Torralba-Martinez A, Lirón-Ruiz R, et al. Intestinal invagination in adults: preoperative diagnosis and management. Int J Colorectal Dis 2004;19(1):68-72

19 Chiang JM, Lin YS. Tumor spectrum of adult intussusception. J Surg Oncol 2008;98(6):444-447

20 Guillén Paredes MP, Campillo Soto A, Martín Lorenzo JG, et al. Adult intussusception - 14 case reports and their outcomes. Rev Esp Enferm Dig 2010;102(1):32-40

21 Ratcliffe JF, Fong S, Cheong I, O'Connell P. Plain film diagnosis of intussusception: prevalence of the target sign. AJR Am J Roentgenol 1992;158(3):619-621
22 Saverino BP, Lava C, Lowe LH, Rivard DC. Radiographic findings in the diagnosis of pediatric ileocolic intussusception: comparison to a control population. Pediatr Emerg Care 2010;26(4): 281-284

23 Weihmiller SN, Buonomo C, Bachur R. Risk stratification of children being evaluated for intussusception. Pediatrics 2011;127(2): e296-e303

24 Wiersma F, Allema JH, Holscher HC. Ileoileal intussusception in children: ultrasonographic differentiation from ileocolic intussusception. Pediatr Radiol 2006;36(11):1177-1181

25 Boyle MJ, Arkell LJ, Williams JT. Ultrasonic diagnosis of adult intussusception. Am J Gastroenterol 1993;88(4):617-618

26 Ciftci F. Diagnosis and treatment of intestinal intussusception in adults: a rare experience for surgeons. Int J Clin Exp Med 2015; 8(6):10001-10005

27 Yakan S, Caliskan C, Makay O, Denecli AG, Korkut MA. Intussusception in adults: clinical characteristics, diagnosis and operative strategies. World J Gastroenterol 2009;15(16): 1985-1989

28 Lioubashevsky N, Hiller N, Rozovsky K, Segev L, Simanovsky N. Ileocolic versus small-bowel intussusception in children: can US enable reliable differentiation? Radiology 2013;269(1): 266-271

29 Munden MM, Bruzzi JF, Coley BD, Munden RF. Sonography of pediatric small-bowel intussusception: differentiating surgical from nonsurgical cases. AJR Am J Roentgenol 2007;188(1): 275-279

$30 \mathrm{Kim}$ YH, Blake MA, Harisinghani MG, et al. Adult intestinal intussusception: CT appearances and identification of a causative lead point. Radiographics 2006;26(3):733-744

31 Rea JD, Lockhart ME, Yarbrough DE, Leeth RR, Bledsoe SE, Clements $\mathrm{RH}$. Approach to management of intussusception in adults: a new paradigm in the computed tomography era. Am Surg 2007;73(11): 1098-1105

32 Lvoff N, Breiman RS, Coakley FV, Lu Y, Warren RS. Distinguishing features of self-limiting adult small-bowel intussusception identified at CT. Radiology 2003;227(1):68-72

33 Jain P, Heap SW. Intussusception of the small bowel discovered incidentally by computed tomography. Australas Radiol 2006; 50(2):171-174

34 Honjo H, Mike M, Kusanagi H, Kano N. Adult intussusception: a retrospective review. World J Surg 2015;39(1):134-138

35 Cakir M, Tekin A, Kucukkartallar T, Belviranli M, Gundes E, Paksoy Y. Intussusception: as the cause of mechanical bowel obstruction in adults. Korean J Gastroenterol 2013;61(1):17-21 